\title{
Produção e Caracterização de Levanasacarase de Bacillus subtilis natto
}

\author{
Gabrielly Terassi Bersaneti ${ }^{1}$ Janaina Mantovan ${ }^{1}$, Dionísio Borsato ${ }^{2}$ e \\ Maria Antonia P. Colabone Celligoi ${ }^{1}$
}

${ }^{1}$ Universidade Estadual de Londrina - Departamento de Bioquímica e Biotecnologia

2Universidade Estadual de Londrina - Departamento de Química

Caixa Postal 10011 - CEP 86.057.970 Londrina - Paraná - E-mail: gaby_terassi@hotmail.com

\section{RESUMO}

O objetivo deste trabalho foi produzir levanasacarase de Bacillus subtilis natto e avaliar os parâmetros cinéticos $\mathrm{pH}$ e temperatura e o efeito da concentração do substrato sacarose na atividade enzimática. $A$ atividade de hidrólise da levanasacarase no extrato bruto obtido do cultivo de B. subtillis natto, após $24 \mathrm{~h}, 150 \mathrm{rpm}$ e $37^{\circ} \mathrm{C}$ foi de $18,7 \mathrm{U} / \mathrm{mL}$. A caracterização parcial demonstrou que as condições ótimas de reação da enzima foram $\mathrm{pH} 6,0$ e $50^{\circ} \mathrm{C}$. $\mathrm{O}$ $\mathrm{Km}$ para sacarose foi de $20 \mathrm{mM}$.

Palavras-chave: levanasacarase; Bacillus subtilis natto; caracterização enzimática, fermentação.

\section{INTRODUÇÃO}

A levanasacarase (EC 2.4.1.10) pertence à família 68 das hidrolases glicosídicas e são conhecidas por catalisar três reações distintas: hidrólise, transfrutosilação e polimerização (CANTAREL et al., 2009), quando o substrato é a sacarose ocorre a liberação de frutose que é convertida em fruto-oligossacarídeos e levana por reação de transfrutosilação em liberação de resíduo de glicose (GORREC et al., 2002).

As condições de fermentação tais como a concentração de substrato, temperatura e pH entre outros, são de grande importância pois podem afetar diretamente a produção de levanasacarase extracelular (LI et al., 2014; GONÇALVES et al., 2013; INTHANAVONG, 2011).

Em processos biotecnológicos o $B$. subtilis tem potencial de aplicação devido ao seu metabolismo com alta capacidade de multiplicação e secreção de proteínas extracelulares (BROOKS; BUTEL; MORSE, 2000).

Sendo assim, esse trabalho teve por objetivo produzir levanasacarase de Bacillus subtilis natto e avaliar a influência do $\mathrm{pH}$, temperatura e o efeito da concentração do substrato sacarose na atividade de hidrólise da enzima. Melhorando o conhecimento bioquímico e dessa enzima para auxiliar sua aplicação industrial.

\section{MATERIAL E MÉTODOS}

O microrganismo utilizado foi o Bacillus subtilis natto. Meio do inóculo composto por ( $\mathrm{g} \mathrm{L}^{-}$ ${ }^{1}$ ): sacarose, 100; extrato de levedura, 2; fosfato monopotássico, 2; sulfato de amônio, 1 e sulfato de magnésio, 0,5. 


\section{VSIMBBTEC}

Londrina 2015

O inoculo foi padronizado a $0,2 \mathrm{~g} \mathrm{~L}^{-1}$ de células e o meio de fermentação composto por ( $\mathrm{g}$ $\mathrm{L}^{-1}$ ): sacarose, 420,7; extrato de levedura, 2; fosfato monopotássico, 1 ; sulfato de amônio, 3; sulfato de magnésio, 0,6; sulfato de manganês, 0,2 e amônio citrato, 0,25 (condição pré otimizada em menor escala). A fermentação foi realizada em Erlenmeyer de $2 \mathrm{~L}$ com $500 \mathrm{~mL}$ do meio de fermentação, em mesa agitadora com $150 \mathrm{rpm}, 24 \mathrm{~h}, 37^{\circ} \mathrm{C} \mathrm{e} \mathrm{pH}$ fixo em 8,0.

A fermentação foi interrompida por centrifugação a $9.050 \mathrm{xg}$ por $15 \min$ a $4{ }^{\circ} \mathrm{C}$. $\mathrm{O}$ sobrenadante foi denominado de extrato bruto (EB) e utilizado como fonte de levanasacarase. A atividade de hidrólise de levanasacarase foi determinada com $250 \mu \mathrm{L}$ de $\mathrm{EB}, 250 \mu \mathrm{L}$ de sacarose $\left(1 \mathrm{~mol} \mathrm{~L}^{-1}\right), 500 \mu \mathrm{L}$ de tampão acetato $\left(50 \mathrm{mmol} \mathrm{L^{-1 }}\right), \mathrm{pH} \mathrm{5,0}$ incubados por 30 min à $30{ }^{\circ} \mathrm{C}$ (ANANTHALAKSHMY; GUNASEKARAN, 1999). Os resultados foram expressos em $\mathrm{U} / \mathrm{mL}$, sendo (U) uma unidade de atividade de hidrólise da levanasacarase.

Para caracterizar a enzima foram utilizados tampões com $\mathrm{pH}$ de 3,0 a 9,0 e as temperaturas variaram de 30 a $90^{\circ} \mathrm{C}$. O efeito da concentração de sacarose na atividade de levanasacarase foi determinado nas condições ótimas de reação $\mathrm{pH} 6,0$ a $50^{\circ} \mathrm{C}$. $\mathrm{O}$ valor de $\mathrm{Km}$ foi determinado pelo método de Lineweaver-Burk descrito por Marzocco; Torres (1999).

\section{RESULTADOS E DISCUSSÃO}

A atividade de hidrólise da levanasacarase no extrato bruto obtido do cultivo de $B$. subtilis natto, após $24 \mathrm{~h}, 150 \mathrm{rpm}$ a $37^{\circ} \mathrm{C}$ foi de $18,7 \mathrm{U} / \mathrm{mL}$. A influência do $\mathrm{pH}$ na atividade da levanasacarase está representada na Figura 1 e a maior atividade foi de $22,6 \mathrm{U} / \mathrm{mL}$ em $\mathrm{pH}$ 6,0, Meng; Futterer (2003) e Ammar et al. (2002) também relataram pH ótimo de 6,0 para a enzima produzida por Bacillus subtilis e Bacillus sp. TH4-2.

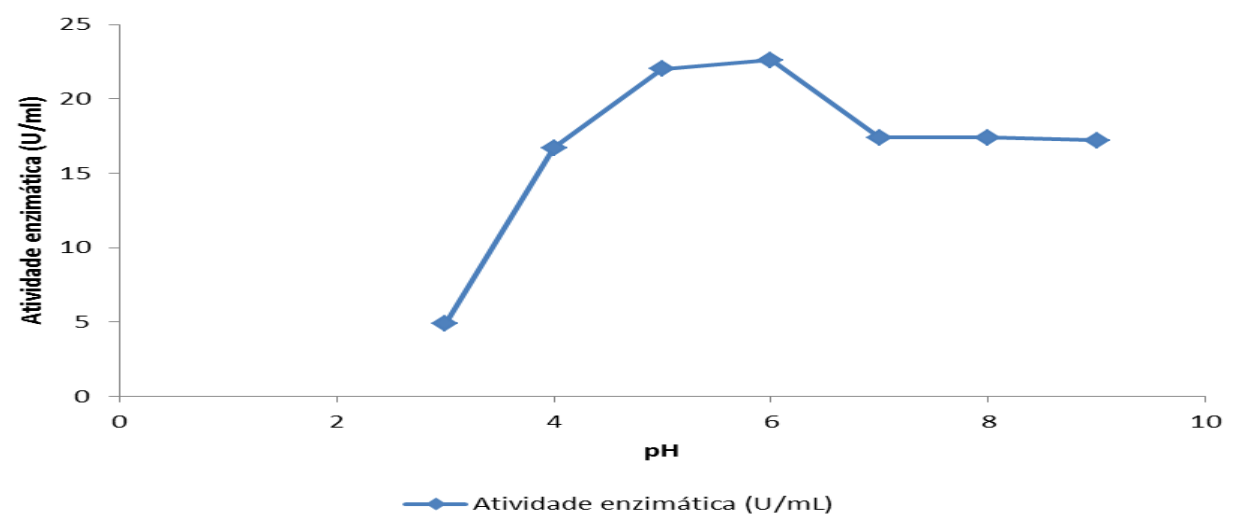

Figura 1. Efeito do pH na atividade de hidrólise da levanasacarase de Bacillus subtilis natto

Dentre as temperaturas utilizadas, $50^{\circ} \mathrm{C}$ foi a melhor para atividade de hidrólise atingindo 26,4 U/mL (Figura 2). Caputi et al. (2013) relataram que a enzima levanasacarase de Erwinia amylovora é ativa em uma ampla gama de temperatura, mas apresentou ótima atividade de hidrólise em $50^{\circ} \mathrm{C}$. Em estudos realizados por Belghith et al. (2012) demonstraram a máxima atividade de levanasacarase, de Bacillus sp foi em $50{ }^{\circ} \mathrm{C}$ mantendo $100 \%$ de sua atividade 
original por mais de $1 \mathrm{~h}$. Também é possível visualizar na Figura 2 que o aumento da temperatura (acima de $50^{\circ} \mathrm{C}$ ) faz com que a atividade enzimática caia drasticamente.

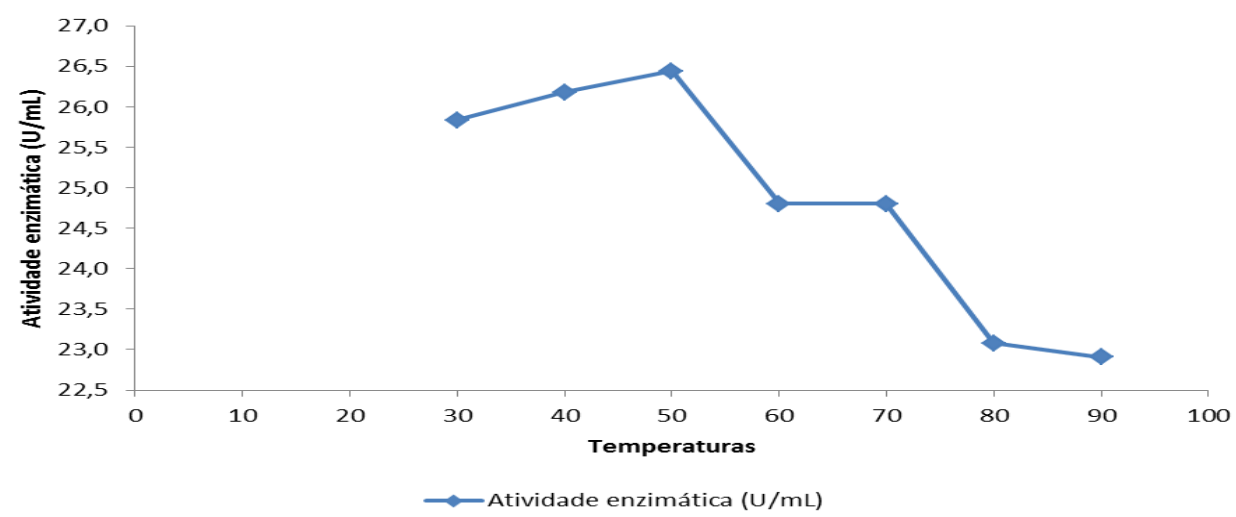

Figura 2. Efeito da temperatura na atividade de hidrólise da levanasacarase por Bacillus subtilis natto.

O Km da levanasacarase para sacarose foi de $20 \mathrm{mM}$ e esse valor está compatível aos valores de $\mathrm{Km}$ reportados na literatura que variam de 4.0 e $160 \mathrm{mM}$ para Bacillus subtilis, Bacillus megaterium e Zymomonas mobilis (CHAMBERT; TREBOUL; DEDONDER, 1974; HOMANN et al., 2007; GOLDMAN et al., 2008).

\section{CONCLUSÕES}

No pH ótimo $(6,0)$ a atividade de hidrólise da levanasacarase aumentou $21 \%$ em relação ao valor obtido no extrato bruto. Esse dado associado à temperatura ótima $\left(50{ }^{\circ} \mathrm{C}\right)$ o valor obtido foi ainda maior 41 \%. Estas informações foram relacionadas ao $\mathrm{Km}$ para a sacarose (20 mM), e são úteis para futuras aplicações industriais da enzima.

\section{REFERÊNCIAS}

AMMAR, Y. B.; MATSUBARA, T.; ITO, K.; IIZUKA, M.; LIMPASENI, T.; PONGSAWASDI, P.; MINAMIURA, N. Caracterization of a thermostable levansucrase from Bacillus sp. TH4-2 capable of producing high molecular weight levan at high temperature. Journal of Biotechnology, v.99, p.111-119, 2002.

ANANTHALAKSHMY, V. K.; GUNASEKARAN, P. Optimization of levan production by Zymomonas mobilis. Brazilian Archives of Biology and Technology, v.42, p.291-297, 1999.

BELGHITH, K. S.; DAHECH, I.; BELGHITH, H.; MEJDOUB, H. Microbial production of levansucrase for synthesis of fructooligosaccharides and levan. International Journal of Biological Macromolecules, v. 50, p.451-458, 2012.

BROOKS, G. F.; BUTEL, J S.; MORSE, S. A. Os estafilococos. In: Brooks GF, Butel JS, Morse SA. Microbiologia Médica. 21. ed. Rio de Janeiro: Guanabara Koogan, p.62-158, 2000.

CANTAREL, B.L.; COUTINHO, P.M.; RANCUREL, C.; BERNARD, T.; LOMBARD, V.; HENRISSAT, B. The Carbohydrate-Active EnZymes database (CAZy): an expert resource for Glycogenomics. Nucleic Acids Research, v.37, p.233-238, 2009.

Universidade Estadual de Londrina - Rodovia Celso Garcia Cid, Pr 445, Km 380 - Campus Universitário Caixa Postal 10.011 CEP 86057-970 Centro de Ciências Exatas - Departamento de Bioquímica e Biotecnologia Fone +55 (43) 3371.4270 - biq@uel.br 
CAPUTI, L.; NEPOGODIEV, S. A.; MALNOY, M.; REJZEK, M.; FIELD, R. A.; BENINI, S. Biomolecular characterization of the levansucrase of Erwinia amylovora, a promising biocatalyst for the synthesis of fructooligosaccharides. Journal of Agricultural and Food Chemistry, v.61(50), p.12265-73, 2013.

CHAMBERT, R.; TREBOUL, G. ; DEDONDER, R. Kinetic Studies of Levansucrase of Bacillus subtilis. European Journal of Biochemistry, v.41, p.285-300, 1974.

GOLDMAN, D.; LAVID, N.; SCHWARTZ, A.; SHOHAM, G.; DANINO, D.; SHOHAM, Y. Two active forms of Zymomonas mobilis levansucrase. An ordered microfibril structure of the enzyme promotes levan polymerization. Journal of Biologycal Chemistry, v.283, p.32209-32217, 2008.

GONÇALVES, B. C. M.; MANTOVAN, J.; LÚCIA, M.; RIBEIRO, L.; BORSATO, D.; CELLIGOI, P. C. Optimization production of thermo active levansucrase from Bacillus subtilis Natto CCT 7712. Journal of Applied Biology and Biotechnology. v.02, p.001-008, 2013.

GORREC, K.; CONNES, C.; GUIBERT, A.; URIBELARREA, J. L.; COMBES, D. Identification of three inducible and extracellular enzymatic activities working on sucrose in Bacillus subtilis NCIMB 11871 and 11872 supernatant. Enzyme and Microbial Technology, v.31, p.44-52, 2002.

HOMANN, A.; BIEDENDIECK, R.; GÖTZE, S.; JAHN, D. SEIBEL, J. Insights into polymer versus oligosaccharide synthesis: mutagenesis and mechanistic studies of a novel levansucrase from Bacillus megaterium. Biochemistry Journal, v.407, p.189- 198, 2007.

INTHANAVONG, L. Production and Characterization of the Fructosyltransferase (Levansucrase) from Geobacillus stearothermophilus and its Application for the Synthesis of Novel Fructooligosaccharides. Tese de doutorado, McGill University, Montreal, Canada, 2011.

LI, R.; ZHANG, T.; JIANG, B.; MU, W.; MIAO, M. Purification and characterization of an intracellular levansucrase derived from Bacillus methylotrophicus SK 21.002. Wiley Online Library, p.1-29, 2014.

MARZZOCO, A.; TORRES, B. B. Bioquímica Básica. Rio de Janeiro: Guanabara Koogan; 1999.

MENG, G. Y.; FÜTTERER, K. Structural framework of fructosyl transfer in Bacillus subtilis levansucrase. Nature

Structural Biology, v.10, p.935-941, 2003.

Universidade Estadual de Londrina - Rodovia Celso Garcia Cid, Pr 445, Km 380 - Campus Universitário Caixa Postal 10.011 CEP 86057-970 Centro de Ciências Exatas - Departamento de Bioquímica e Biotecnologia Fone +55 (43) 3371.4270 - biq@uel.br 